\title{
Habituation of the psycho-galvanic reflex in patients with anxiety states and in normal subjects
}

\author{
M. H. LADER AND LORNA WING \\ From the Institute of Psychiatry, Maudsley Hospital, London, and the Department of Pharmacology, \\ University College, London
}

Anxiety is a term which has had many meanings. It may refer to a commonly experienced emotion, to a personality variable, to a symptom accompanying physical or mental illness, or it may be a symptom occurring in relative isolation. Patients who complain primarily of feelings of fear or anxiety, occurring either continually or in attacks, without organic basis or any other marked psychiatric symptoms, may be referred to as suffering from anxiety states. In these patients, symptoms referable to the autonomic nervous system, such as palpitations and cold, clammy hands, are common.

It has been postulated (Malmo, 1957, 1959) that patients with anxiety states are chronically 'overaroused'. The term 'level of arousal' is widely used by psychologists to refer to a hypothetical continuum ranging from sleep through normal waking to terror and anger. Much earlier, the similar term 'level of vigilance' was introduced by Sir Henry Head (1923) based on physiological observations. Head regarded the level of vigilance of any part of the central nervous system as reflecting its high-grade 'physiological efficiency', which could be lowered by sleep or chloroform thus lessening its efficiency of responsiveness.

One of the most extensively used indices of the level of vigilance in man is the electrical resistance of the palmar skin which is dependent on sweat-gland activity (Lader and Montagu, 1962). Three aspects of the skin resistance are commonly studied: first, the background level, which is a measure of normal continuing sweat-gland activity; secondly, variations in the rate of sympathetic, sudomotor discharge result in 'spontaneous fluctuations' which can be counted; and thirdly, responses to specific external stimuli can be measured. Such responses are termed psycho-galvanic reflexes or galvanic skin responses.

If identical, discrete stimuli are repeated, the psycho-galvanic reflex tends to diminish in size or 'habituate'. Also, the background levels may alter during a series of stimuli. Such a change in the direction of those levels obtaining before the stimulop started will be termed 'adaptation'.

The purpose of the experiments to be described was to use a relatively simple stimulus situation tơ detect differences between patients with anxiety states and normal control subjects with respect to the various aspects of palmar resistance. We werE especially interested in any differences in the mean rates of habituation between the two groups, as this relatively simple property of the central nervous system has not been extensively studied.

\section{METHODS}

MEASUREMENT OF SKIN RESISTANCE The technique for the measurement of skin resistance has been reported in elsewhere (Lader, 1964) and the following is a summapy

The electrodes were made of lead and of the doubete element type to avoid polarization difficulties (Lykken1959). The inactive electrode was placed on the latefab aspect of the arm above the elbow. The site was prepared by rubbing briskly with an emery board. The active electrode site was the distal phalanx of the right thumb An annular foam-plastic corn-plaster of internal diamete? $9.5 \mathrm{~mm}$. was placed symmetrically over the central arch or whorl of the thumb print to act as a masking device At both electrode sites an electrode jelly containing $0.05 \mathrm{M}$ sodium chloride as the electrolyte was used There was no preparation other than wiping dry at the active electrode site.

A constant current of 10 microamperes was passect through the electrodes and the voltage engendered was balanced back in steps of $0.25 \mathrm{v}$. (equivalent to 25 kilohms) to the nearest $0 \cdot 25 \mathrm{v}$. Sensitivities equivalent to full-scale deflections of \pm 100 kilohms, \pm 50 kilohms, and \pm 25 kilohms were available. The residual voltage was fed into a Grass Driver amplifier and hence to oneo channel of a Grass polygraph. An ink-writing pen oscillograph at a chart speed of $1.5 \mathrm{~mm}$./sec. providedo the record.

STIMULATION PROCEDURE Twenty identical auditory stimuli were applied in a predetermined sequence at intervals varying randomly from 45 to 80 seconds." Each stimulus was a 1,000 c.p.s. pure tone of one second's $N$ duration. Before each experiment, the tone was standard- 
ized as 1 volt across a 3-ohm loudspeaker. Measured with a Dawes sound-level meter, the intensity was found to be $100 \mathrm{db}$ above a reference source of 0.0002 dynes/sq.cm.

EXPERIMENTAL CONDITIONS The subject sat in a comfortable arm-chair with a padded arm-rest. The room was sound-protected in a quiet part of the building. Its temperature was controlled at 22 to $24^{\circ} \mathrm{C}$. The recording equipment was in an adjoining room and the leads passed through the intervening wall.

PATIENTS Twenty patients suffering from anxiety states who presented at the Maudsley Hospital either as in-patients or as out-patients participated in the study. Such patients usually complained of symptoms referable to the autonomic nervous system such as palpitation, cold and clammy hands, dry mouth, difficulty in swallowing, and diarrhoea. In 17 of the patients the anxiety was present all the time and was 'free floating', but in the other three it was severe only in certain situations, such as travelling on public transport. The latter group are sometimes described as 'phobic' but in this paper the term will be avoided because of the confusion of meaning which surrounds it (Lewis, 1956). Instead the syndrome will be referred to as 'situational' anxiety state.

Patients were excluded if anxiety was obviously secondary to some other illness, e.g., depression or early schizophrenia. If the anxiety state was the primary and predominant feature, the presence of some mild depressive symptoms did not exclude the patient, that is, if the patient spontaneously emphasized his fears and physical symptoms and produced such symptoms as disinterest and lethargy only on careful questioning, he was included.

All patients who presented with the above clinical picture were asked to participate and the research nature of the procedure was emphasized. Two patients refused to take part because they felt too apprehensive; otherwise, 10 consecutive male patients and 10 consecutive female patients underwent the tests.

Of the men, one had a situational anxiety state, one suffered from mild depression as well as anxiety; the remaining eight patients all had free-floating anxiety. Two of the women had situational anxiety states, one had mild depressive features in addition to anxiety, and seven were suffering from free-floating anxiety.

The ages of the patients ranged from 19 to 53 years with a grossly positively skewed distribution. Log transformation normalized the ages. The mean log age was for the males $1.51(=32$ years $)$ and $1.42(=26$ years $)$ for the females. However, the log age difference between the sexes was not significant $(t=1 \cdot 80)$.

The duration of illness ranged from four weeks to 19 years, but the duration was less than one year in 10 of the 20 patients.

NORMAL CONTROL SUBJECTS For every patient, there was a control subject of the same sex and within two years of the same age. Of the males, six were hospital porters, two were laboratory technicians, and two were on the medical staff. Six of the females were secretaries, three were technicians, and one was a nursing sister. They were asked to take part because they were of the appropriate age and sex and not because they were believed to be 'relaxed' individuals. However, one porter was excluded from the study before physiological recording even began because of his obvious overt anxiety. He asked for many reassurances about the safety of the procedure and emphasized that he had family responsibilities. It is of interest that his skin resistance tracing was typical of an anxious patient.

RATINGS OF OVERT ANXIETY Each patient was interviewed personally by one of us (L.W.) to confirm the suitability of that patient for inclusion in the study. The nature of the test was explained and after the patient had consented to participate, he was brought into the experimental room and the electrodes were placed in position. Before the recording started, one of us (L.W.) rated the patient for overt anxiety on a seven-point scale ranging from 0 -no overt anxiety to 6-very severe anxiety. The rating was based on observations made during the preparations for recording, and not on the patient's history. This distinction is particularly important in the case of patients suffering from situational anxiety states. The factors taken into account were verbal behaviour (desire for reassurance, questions about the safety and comfort of the procedure, pressure of talk, and unsteadiness of voice) and bodily posture and movements (apprehensive facial expression, tendency to sit on the edge of the chair even when asked to lean back, restlessness, and tremor).

No attempt was made to rate each of these symptoms and signs individually. The rating was based on the overall impression.

EXPERIMENTAL PROCEDURE After the above preliminaries, the patient was asked to make himself as comfortable as possible and to relax as far as he was able. Reassurance was given if necessary and the right of every subject to withdraw at any stage of the test was stressed. (Every patient completed the test.) The patient was informed that after a rest period, he would hear a series of sounds to which he was to make no active response.

The main lights were switched off leaving only a desk lamp illuminated, and the patient was left alone in the room. Recording was started and the patient was left at rest for 11 minutes. The 20 auditory stimuli were then applied and recording terminated one minute after the last stimulus.

\section{ANALYSIS OF SKIN RESISTANCE RECORDINGS}

SKIN CONDUCTANCE LEVELS The skin resistance was read at one-minute intervals before the stimuli started, just before each of the 20 stimuli, and at the very end of the experiment. The skin resistance readings were converted to log conductance for reasons which have been outlined elsewhere (Lader, 1964). The $32 \mathrm{log}$ conductance values were averaged in groups of four to yield eight values, three during the rest period and five during the stimulation procedure.

PSYCHO-GALVANIC REFLEXES The skin resistance was read at the lowest point of each psycho-galvanic reflex 
and converted to log conductance. The log conductance value at the beginning of the response was subtracted from it to give the psycho-galvanic reflex quantified in terms of change in log conductance.

SPONTANEOUS SKIN CONDUCTANCE FLUCTUATIONS The skin resistance fluctuations were counted for 40-second periods out of the minute intervals before the stimuli started; for 40 -second periods before each of the stimuli; and for the final 40 seconds before the end of the experiment.

The criterion used was a log conductance one of 0.003 $\log \mu$ mhos and the technique for applying this criterion to a resistance record has been explained elsewhere (Lader, 1964).

The 32 counts were added into eight groups of four, three during the rest period and five during the stimulation procedure.

STATISTICAL ANALYSIS Although the experimental design was really of the matched-pairs (split-plot) type, this analysis of variance was not used because the variances attributable to age were relatively small. Therefore, a simple two-way analysis of variance was used with groups (patients and controls) and sexes as the sources of variance. As no significant between-sexes effects were found the between-group results only will be presented.

\section{RESULTS}

Examples of typical skin resistance records from a normal subject and a patient with anxiety state are shown in Figure 1. For the normal subject the skin resistance level is about $215 \mathrm{kilohms}$ and it is rising slightly (i.e., conductance is falling). There are no responses to the stimuli and only a few spontaneous fluctuations in the skin resistance record can be discerned. For the anxious patient, the skin resistance level is much lower ( 50 kilohms) with no tendency to rise. There are small but definite responses (psycho-galvanic reflexes) to the stimuli and many spontaneous fluctuations. The trace gives the impression of ceaseless activity.

SKIN CONDUCTANCE LEVELS (SWEAT-GLAND ACTIVITY) The effects of the 20 auditory stimuli on the mean

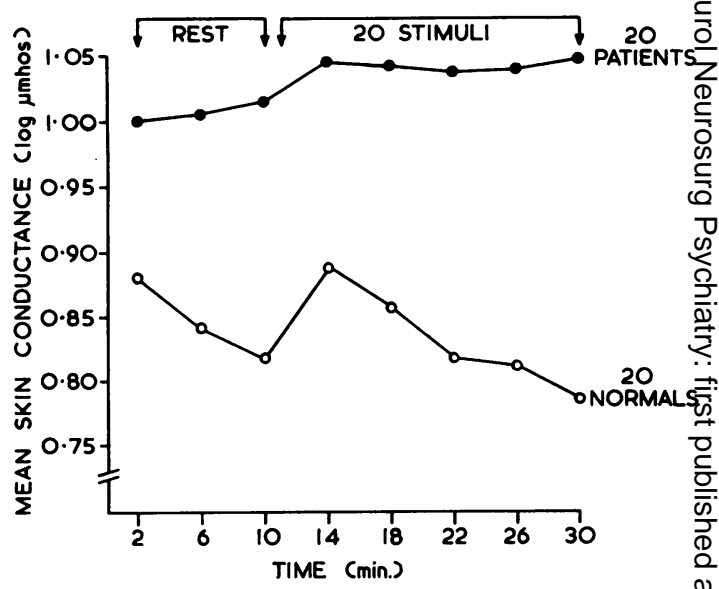

FIG. 2. The effects of 20 auditory stimuli on the skin conductances. Each point represents the mean of four log conductance readings.

log skin conductance levels in the control anథ patient groups are depicted in Figure 2. During the rest period before the stimuli the skin conductance drops rapidly in the control subjects. A rise occiriss in response to the first few stimuli followed bo second drop. At the end of the experiment (time 309 the mean conductance level is much less than at $\$$ start of the experiment (time 2).

For the patients with anxiety states, the meas skin conductance rises slightly during the period, rises more abruptly in response to the first few stimuli and it tends to persist at this high lege during the remainder of the stimulus sequence.

The relevant statistical data are summarized iQ Table I. The difference between the groups for tho skin conductance levels reaches the 0.05 level of significance at the end of the rest period (time 10) This significance is lost at the next point (time 14) af the time of the first few stimuli but reappears $a \overrightarrow{\bar{\phi}}$ time 18 and continues. At the end of the experimen (time 30) an F-ratio of 10.97 (d.f.: 1,$36 ; \mathrm{P}<0.01$

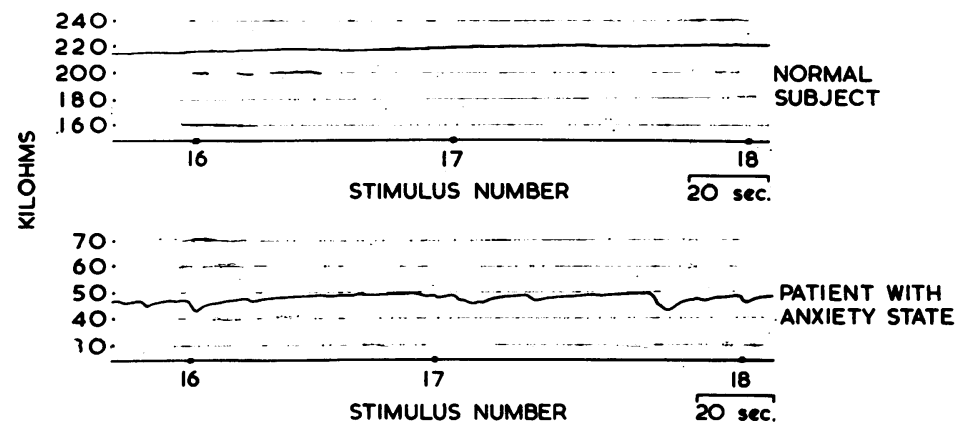

FIG. 1. Examples of skin resis ance traces from a normal subject and a patient with anxiety state. 
TABLE I

SKIN CONDUCTANCE DATA

\begin{tabular}{|c|c|c|}
\hline \multirow[t]{2}{*}{ Variable } & \multicolumn{2}{|c|}{ Patients v. Normals } \\
\hline & F-ratio & $P$ \\
\hline Skin conductance at time 2 & $<2$ & Nil \\
\hline Skin conductance at time 6 & $<4$ & Nil \\
\hline Skin conductance at time 10 & $4 \cdot 93$ & $<0.05$ \\
\hline Skin conductance at time 14 & $<4$ & Nil \\
\hline Skin conductance at time 18 & 5.06 & $<0.05$ \\
\hline Skin conductance at time 22 & 4.91 & $<0.05$ \\
\hline Skin conductance at time 26 & $8 \cdot 20$ & $<0.01$ \\
\hline Skin conductance at time 30 & 10.97 & $<0.01$ \\
\hline \multicolumn{3}{|l|}{ Change in skin conductance } \\
\hline Time 2 minus time 10 & $8 \cdot 00$ & $<0.01$ \\
\hline Time 10 minus time 14 & $<2$ & Nil \\
\hline Time 14 minus time 30 & 13.94 & $<0.001$ \\
\hline Time 2 minus time 30 & $21 \cdot 03$ & $<0.001$ \\
\hline
\end{tabular}

is obtained for the difference between the two groups.

The change in log conductance during the rest period (time 2 minus time 10) is significantly different between the two groups $(P<0.01)$, as is the change during the stimuli (time 14 minus time 30) $(P<0.001)$. The latter result may be interpreted as meaning that adaptation of the skin conductance to a stimulus situation is substantially impaired in patients with anxiety states as compared with normal subjects.

The variable which produced the highest F-ratio between the groups was the change in log conductance throughout the whole experiment (time 2 minus time 30). This variable will be referred to subsequently as 'total conductance change'. Although a high F-ratio was obtained ( 21.03 d.f.: 1,$36 ; \mathrm{P}<0.001)$, there was still some overlap between the values for this variable for the two groups. The overlap was such that if a line were drawn through the values for the two groups in such a way as to minimize the values overlapping, a total of seven subjects would still be misclassified. That is, four patients' values would lie in the region of the normal subjects' values; three normals' values would extend into the region occupied by the patients' values.

PSYCHO-GALVANIC REFLEXES (SWEAT-GLAND RESPONSES) It was known from previous work (Lader, 1964) that habituation of the psycho-galvanic reflexes followed an exponential course. Therefore, the mean psycho-galvanic reflexes (ordinate $Y$ ) were plotted against the logarithm of the stimulus number (abscissa $\mathrm{X}$ ). The results obtained for both groups are shown in Figure 3.

The first responses are distinct but responses 2 to 20 inclusive form a straight line for each group. The regression lines of mean responses on log stimulus number were calculated in the usual way (Snedecor, 1956) and the equations are:

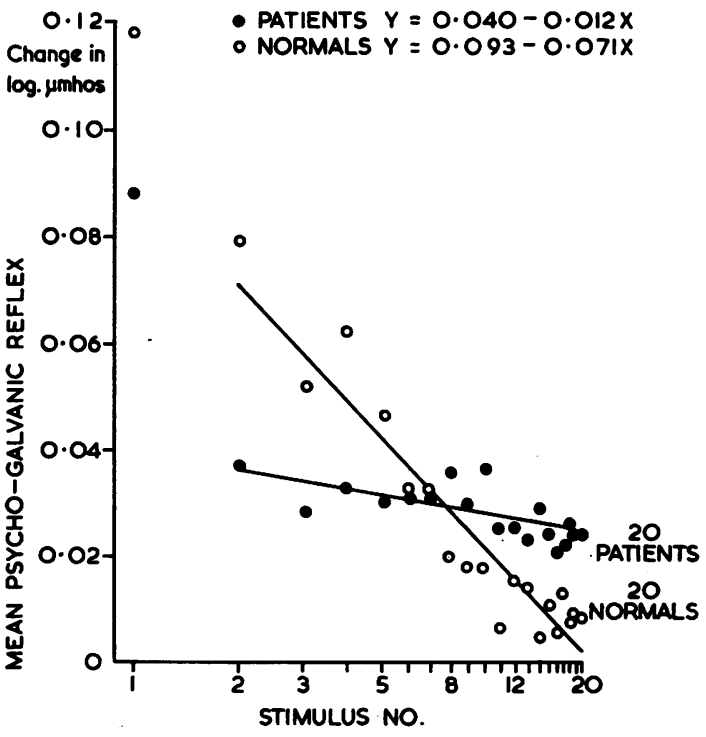

FIG. 3. Habituation regression lines of the psychogalvanic reflex.

For patients, $\quad \mathrm{Y}=0.040-0.012 \mathrm{X}$

For normals, $Y=0.093-0.071 \quad X$

The constants 0.040 and 0.093 represent ' $a$ values', the Y-intercepts, i.e., the points on the $Y$-axis which would be intersected by the regression lines if they were extrapolated to the left, to the $\mathbf{X}=\mathbf{O}$ position (stimulus one). The higher avalue for the normals suggests that they tend to have larger earlier responses than the patients.

The constants -0.012 and -0.071 are 'b-values', the slopes of the lines or regression coefficients. The more negative the constant, the steeper the slope, i.e., the more rapid is habituation. The more negative value for the normals suggests a more rapid rate of habituation than for the patients.

For each of the 40 subjects, a regression equation, each with an a- and a b-value, was calculated. An additional complication which arose was that many of the normal subjects habituated to zero response often as early as the tenth stimulus. It was decided to adopt an arbitrary criterion for assessing when complete habituation had occurred. The criterion was that when three consecutive stimuli failed to elicit an observable response, complete habituation was deemed to have occurred. Therefore, when calculating the habituation regression line, the third zero response was regarded as the end of the sequence of responses and any later responses due to dishabituation were disregarded.

Next, a correlation of $-0.81 \quad(P<0.001)$ was found between the a-values and the b-values. That 
is, those subjects with large early responses tended to have steeper slopes of habituation. Therefore, each of the b-values was corrected for its dependence on its corresponding a-value by routine regression techniques (Snedecor, 1956). One score, the 'habituation-score' (H-score) was obtained for each subject which was the slope of habituation corrected for the Y-intercept.

The statistical results are given in Table II. There is no significant difference between the two groups for the size of the first response. The a-values are significantly higher in the normal subjects than in the patients with anxiety states $(P<0.01)$. The b-values are significantly more negative $(P<0.001)$ for the normals than for the patients. Similarly, the $\mathrm{H}$-scores are significantly more negative $(\mathrm{P}<0.001)$ for the normals than for the patients although the F-ratio is less than that for the uncorrected b-score.

TABLE II

HABITUATION DATA

\begin{tabular}{lll} 
& \multicolumn{2}{c}{ Patients v. Normals } \\
\cline { 2 - 3 } & F-ratio & $P$ \\
\hline First psycho-galvanic reflex & $<1$ & Nil \\
a-value & 11.65 & $<0.01$ \\
b-value & 27.67 & $<0.001$ \\
H-score & 17.66 & $<0.001$
\end{tabular}

The $\mathrm{H}$-scores yielded very high discrimination between the groups. It was possible to draw a line through the two sets of $\mathrm{H}$-scores so that only one normal and one patient were misclassified.

Summarizing, the normal subjects have larger early responses than the patients. They habituate more rapidly than the patients even when their larger early responses are taken into account. Also, the habituation-scores yield a fairly clear-cut demarcation between the two groups.

'HABITUATORS AND NON-HABITUATORS' When the regression slopes (b-values) were calculated for each subject, the significance of each regression slope could be tested (Snedecor, 1956). If the slope was significantly negative at the $\mathbf{0 . 0 5}$ level of confidence or beyond, then habituation was considered to have occurred. If the slope did not reach the 0.05 level of confidence, habituation was deemed not to have occurred. Therefore, the subjects could be categorized as 'habituators' or 'non-habituators'.

All 20 of the normal subjects were 'habituators', whereas only six of the patients were 'habituators'. These values could be cast into a four-fold contingency table for which the $\chi^{2}$ value was 18.55 (1 d.f.; $\mathbf{P}<0.001)$. It may be concluded that

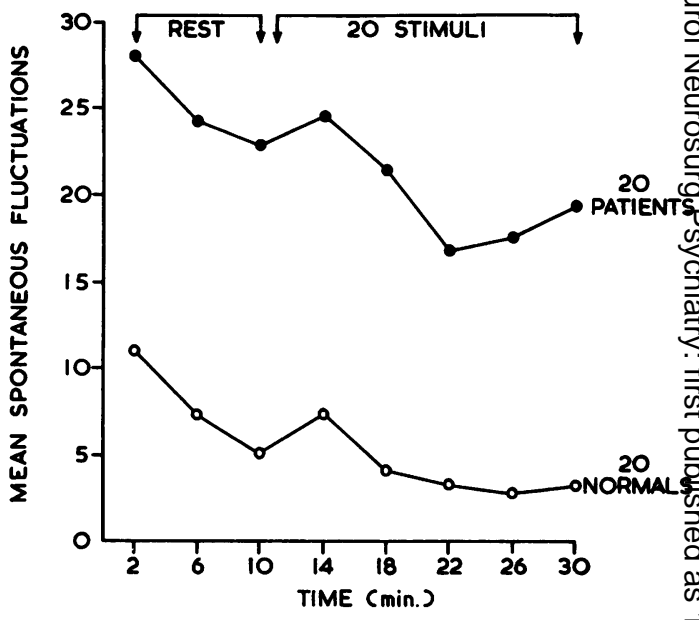

FIG. 4. The effects of 20 auditory stimuli on the number $\overrightarrow{\mathscr{f}}$ spontaneous skin conductance fluctuations. Each poimt represents the mean number of fluctuations counted fon four periods of 40 seconds.

significantly fewer patients were 'habituators' thain the normals.

SPONTANEOUS SKIN CONDUCTANCE FLUCTUATION (sWEAT-GLAND FLUCTUATIONS) The effects of ghts 20 auditory stimuli on the mean number of spontameous fluctuations for the patient and control groups are shown in Figure 4. For both groups, there $\frac{8}{8}$ steady decline in the mean number of fluctuations during the rest period, a small increase in respoms to the first few stimuli and then a second decrease Finally, the mean number for the patient group tends to increase at the end of the experiment.

There are highly significant differences betwee the groups for the number of spontaneous fluctug ations at all stages of the experiment. The numbers of fluctuations at times 26 and 30 were adde together to give a variable which will be referred to subsequently as 'fluctuations at end of experiment For this variable, an F-ratio of 48.78 (1,36 d.f. $P<0.001$ ) was obtained for the difference between groups (Table III).

No significant differences were found for any of the variables of change in number of spontaneous. fluctuations. This suggests that both groups ref sponded similarly to the experimental situation as gauged by the fluctuations in contrast to the skip conductance levels where the trends especially were different.

The fluctuations at the end of the experiment enabled a fairly high discrimination to be draw between the groups. Three subjects, two patients and one normal, would have been misclassified. 
TABLE III

SPONTANEOUS FLUCTUATIONS DATA

Variable

Patients v. Normals

\begin{tabular}{ll} 
Patients v. & Normals \\
\hline F-ratio $P$
\end{tabular}

Spontaneous fluctuations at time 2

Spontaneous fluctuations at time 6

Spontaneous fluctuations at time 10

Spontaneous fluctuations at time 14

Spontaneous fluctuations at time 18

Spontaneous fluctuations at time 22

Spontaneous fluctuations at time 26

Spontaneous fluctuations at time 30

Spontaneous fluctuations at time 26 plus time 30

Changes in spontaneous fluctuations

Time 2 minus time 10

Time 10 minus time 14

Time 14 minus time 30

Time 2 minus time 30

$\begin{array}{ll}30.89 & <0.001 \\ 35.61 & <0.001 \\ 41.92 & <0.001 \\ 32.87 & <0.001 \\ 44.92 & <0.001 \\ 33.77 & <0.001 \\ 55.13 & <0.001 \\ 40.12 & <0.001 \\ & \\ 48.78 & <0.001 \\ & \\ <1 & \text { Nil } \\ <1 & \text { Nil } \\ <2 & \text { Nil } \\ <1 & \text { Nil }\end{array}$

DISCRIMINANT-FUNCTION ANALYSIS AND OVERT ANXIETY RATINGS Three variables yielded high F-ratios between the groups and were able to discriminate between the groups to a greater or lesser extent. These variables were total conductance change, $\mathrm{H}$-score, and fluctuations at the end of the experiment. It was decided to combine the three variables in such a way as to maximize the discrimination between the groups. This technique is known as discriminant-function analysis (Fisher, 1954). The technique, although empirical, is invaluable as a combining procedure when several variables have been measured. In the present case, the equation derived was: Discriminant-function score $=-0.074$ (total conductance change) +0.485 (H-score) +

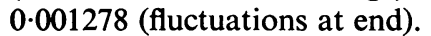

The discriminant-function score (D-score) was calculated for each subject. The D-score may be taken as an estimate of 'composite physiological activity'. The F-ratio between the groups for the D-scores was 68.97 (1,33 d.f.; $P<0.001)$. Dis- crimination was quite high, only three subjects, two patients and one normal, being misclassified (see Fig. 5).

It is obvious from Fig. 5 that one patient (marked 'd.r.') gave a D-score which was well into the normal range. This patient, a woman, appeared fairly anxious before the test, and for the first two-thirds of the recording session the trace obtained was very active with a low skin resistance, many fluctuations and persisting responses to the stimuli. The activity increased and then, fairly suddenly, it decreased; the skin resistance soared upwards, the fluctuations diminished greatly in number and the responses habituated almost to zero. On questioning the patient afterwards, she reported that she felt a panic attack coming on about two-thirds of the way through the session. The feeling of panic increased until she felt that she would have to ask for the recording to be stopped. However, the feeling of panic suddenly subsided and instead she felt that her surroundings were no longer real, that the walls of the room had disappeared and that there were no recording electrodes attached to her arm: phenomena of 'derealization'. This subjective feeling persisted until the end of the experiment.

In Fig. 5 are plotted out the D-scores as abscissa and the overt anxiety ratings as ordinate. Two of the patients who had situational anxiety states appeared unaffected by the proceedings and were rated at zero. The third patient with situational anxiety was afraid of new situations and she appeared fairly anxious (rating 4). Two patients were rated as 6 as their anxiety was extreme, almost agitation.

The Spearman rank correlation coefficient (corrected for tied ranks, Siegel, 1956) between the D-scores and the overt anxiety ratings was +0.66 $(\mathrm{P}<0.002)$. It is also apparent that the majority of points lie in a fairly narrow band but that five points lie outside this region. Of these five one point

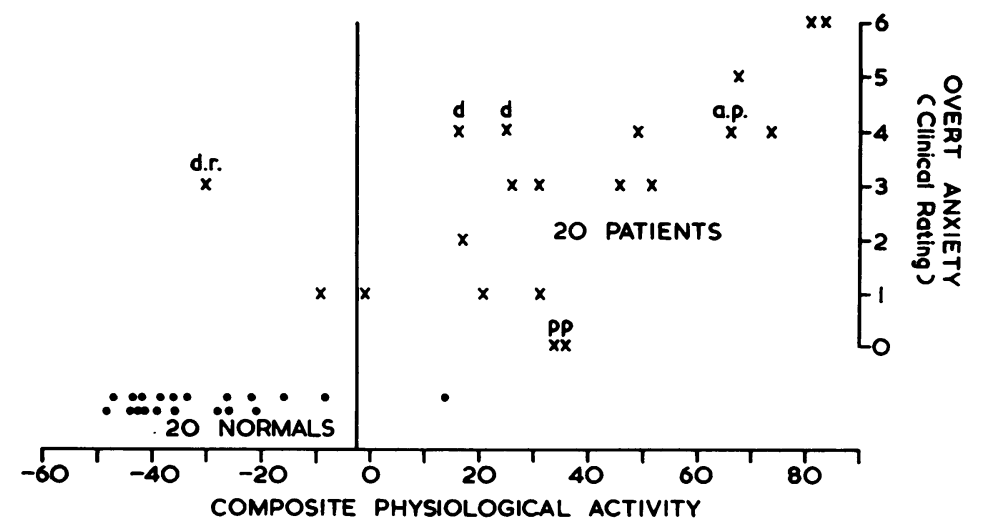

FIG. 5. Relationship between composite physiological activity ( $D$ scores) and clinical ratings of overt anxiety for 20 patients. The $D$ scores for 20 matched normal subjects are also shown. 
(d.r.) is that from the patient who underwent feelings of derealization during the experiment. Two points (p) were obtained from the two pat:ents with situational anxiety states who were rated at zero. Two points (d) were obtained from the two patients who had anxiety states plus some depression. The remaining cases comprised 14 patients with free-floating anxiety states plus one with a situational anxiety state who was made anxious by the novel situation (a.p.). The rank order correlation coefficient between the $D$-scores of these 15 patients and their ratings of overt anxiety was $+0.93(\mathrm{P}<0.001)$. Therefore, there is a very high correlation between 'composite physiological activity' during the test and overt anxiety preceding it.

\section{DISCUSSION}

The patients used in the present experiment all suffered from anxiety which was severe enough for their general practitioner to refer them for psychiatric advice. In 15 of these patients the anxiety was free-floating and it is probable that these patients formed as homogeneous a group as one is likely to encounter in clinical psychiatry. In these patients the correlation between a composite physiological activity score and rating of overt anxiety was high. However, the addition of the patients with situational anxiety states or anxiety with depression diluted this relationship considerably. This illustrates the necessity for using homogeneous groups of experimental subjects, a factor which was emphasized many years ago by Darrow (1933).

The normal subjects were not chosen because they were known to be 'relaxed' subjects as in some experiments (e.g., Ackner, 1956). Apart from one very apprehensive subject who was excluded, the normal subjects were accepted without enquiry about personality. Conclusions about the differences between such a group of control subjects and a group of patients with anxiety states may be drawn more widely than those obtained from a comparison of anxious patients with relaxed normals.

Malmo, Shagass, Davis, Cleghorn, Graham, and Goodman (1948) advocated the use of a standardized laboratory situation as a means of showing up physiological differences between psychiatric patients and normal subjects. Simple stimuli such as thermal pain (Malmo and Shagass, 1949) or white noise (Davis, Malmo, and Shagass, 1954) have been used. In the present experiments, it was our intention to study habituation to a series of stimuli and we were not primarily attempting to induce subjective feelings of anxiety in the patients. However, spontaneous reports by some of the patients indicated that subjective anxiety was experienced, but this was in response to the unfamiliar laboratorf situation rather than to the individual stimuli.

It has been previously described that the skim conductance is higher in anxious patients than if normal subjects (Darrow and Solomon, 1934? Solomon and Fentress, 1934; Howe, 1958). Similarl $\$$ Malmo et al. (1948) and Ödegaard (1932) reported that spontaneous fluctuations in the skin resistancos record were more frequent in anxious patients tha $\frac{}{1}$. in normal subjects. In the present experiments, both these variables were substantially and significantly raised in the patients. As these variables are widel $\overrightarrow{\vec{r}}$ : regarded as indicants of the level of general cerebrad vigilance (level of arousal) these results are if accordance with the view of Malmo (1957, 1959). that anxious patients are chronically overaroused. $\widetilde{\Phi}$

The number of fluctuations and the skin conduc ance in the normal subjects pursued similar courses throughout the experiment. It is possible to regar $\bar{\Phi}$ them as alternative indicators of the level of generat central nervous system activity. However, in the patients, the trends were different for the two variables: the conductance rose whilst the number of fluctuations fell. Therefore, in the patients, this two variables are reflecting somewhat differents aspects of the level of central nervous sysermu activity. A unitary theory of arousal or vigilance would be insufficient to account for these results $\Omega$ 음

As far as the early responses (two to four) concerned the patients were less reactive than the normals. This confirms the findings of Ödega (1932), Solomon and Fentress (1934), Darrow 希苑 Solomon (1934), and Wishner (1953) but is contradiction to those of Hoch, Kubis, and Rouke (1944). The lowered reactivity of the patients is im accord with the law of initial values of Wildes $(1958,1962)$. This states that the greater the state of excitation at the moment of onset of the stimuluso the weaker will be the additional excitation. As the patients tended to be overactive physiologically $\vec{Q}$ presumably reflecting excess central nervous system excitation, stimuli would be expected to have little additional effect and small responses would result.

Habituation was undoubtedly slowed down patients with anxiety states as compared with the normal subjects. This was true even if the smalle early responses of the patients were taken into. account. Some of the patients hardly habituated a\& all and the responses to the later stimuli were similar in magnitude to those to the earlier stimulio This lack of habituation was often very striking and even when the number of spontaneous skin conducto ance fluctuations had fallen considerably, the psycho-galvanic reflexes to the stimuli continued undiminished. Adaptation of the skin conductance् to the series of stimuli, i.e., time 14 minus time $30 \mathrm{~W}$ 
was also significantly impaired in the anxious patients.

Impairment of habituation and adaptation appears to be a characteristic feature of anxious patients. Stewart, Winokur, Stern, Guze, Pfeiffer, and Hornung (1959) reported that a group of 10 patients with anxiety states took significantly more trials to reach zero response to a series of 500 c.p.s. tones of $65 \mathrm{db}$ intensity than either a group of 18 schizophrenics or a group of 27 manic-depressive psychotics. As no control group was used, it is impossible to state whether the anxious patients also habituated more slowly than normal subjects. Impaired adaptation has been reported for other measures, for example, E.E.G. (Ellingson, 1954), blood-pressure (Malmo, Shagass, and Heslam, 1951; Jurko, Jost, and Hill, 1952), and electromyogram (Davis et al., 1954). Often, anxious patients themselves will specifically complain of 'inability to relax' even under quiet conditions. Furthermore, difficulty in falling asleep is a fairly common symptom.

In previous experiments with normal subjects (Lader, 1964) a significant correlation was found between the rate of habituation and the number of fluctuations, slow habituation being associated with frequent fluctuations. Furthermore, the administration of cyclobarbitone diminished the number of fluctuations and the skin conductance level and accelerated habituation. It seems apparent that the rate of habituation is partially dependent on the level of activity as Scholander (1960) had previously suggested. But there are still wide individual differences in the rates of habituation even allowing for differences in levels of activity. There appears to be some relationship with age in that the student subjects used in the previous experiment (Lader, 1964) tended to habituate less rapidly than the normal subjects of wider age group used in the present experiment.

The relationship between level of central nervous system activity and habituation enables some interesting processes to be discerned. If the level of activity obtaining at any moment is low, the intrusion of a repetitive or continuing stimulus situation has only a brief effect in raising the level of activity as the ensuing habituation is not only rapid but it accelerates as the level of activity returns to the pre-stimulus level. Conversely, if the level of activity is high, habituation to the stimuli is slow, especially at first. If the subject is overactive, no habituation occurs; instead, the level of activity becomes even higher with each successive stimulus and a vicious circle results. Such a positive feed-back system represents a danger to the organism in that it results in excessive excitation in the central nervous system.
Summarizing, the main results of this experiment are: first, that patients with anxiety states are overactive physiologically and that the degree of physiological activity is closely related to the severity of the overt anxiety estimated clinically. Secondly, the rate of habituation is greatly diminished in patients with anxiety states and this parameter enables a high discrimination to be made between such patients and normal subjects. And also it is known from previous experiments that there is a relationship between level of activity and rate of habituation. Of the several hypotheses which could be put forward to link these findings, the following preliminary one is selected as it is the simplest.

In the population at large, habituation and adaptation are properties of the central nervous system which are distributed on a continuum, and any individual's locus on that continuum is mainly determined by genetic factors. At one end of the continuum are a group of people who are slow to habituate even under normal conditions. If a stressful situation is encountered by a normal subject, his level of central nervous system activity is raised and he feels anxious. However, he proceeds to adapt to the stimulus, his level of activity falls, and the anxiety is therefore transitory. In a subject who habituates slowly, the stimulus raises his level of activity and retards still further an already slow rate of habituation. If the stimulus is powerful enough and the subject's rate of habituation is normally very slow, a positive feed-back system is set in action which results in a very high level of central nervous system activity and feelings of continued marked anxiety or a panic attack. In this state, removal of the precipitating cause may have little or no effect as it merely acted as a trigger in setting off excess central nervous system activity which becomes self-perpetuating. In this scheme, derealization may be caused by excess, powerful, corticofugal inhibition which damps down the positive feed-back but also distorts the interpretation of sensory inflow.

Several experiments are at present being performed in order to examine some of the points in the above scheme. The effect of sedative drugs should be to alter the physiological measures towards the normal pattern and it is hoped that formal bio-assays of such drugs will prove possible. A twin-study of habituation is being carried out by us as a first step in the elucidation of the inheritance of habituation rates. In another study in progress, stimulant drugs are being administered to normal subjects and the relationship between physiological changes and any subjective feelings of anxiety observed.

The above hypothesis is only a very rough and tentative first approach to the interpretation of the 
physiological findings of the present experiment. Whilst a laboratory experiment has the immense advantage of allowing simplification and reproducibility of the experimental situation, extrapolation from the laboratory to real-life situations must always be done with caution. However, this method of approach to the problem of anxiety appears promising.

\section{SUMMARY}

The palmar skin resistance was recorded in 20 patients with anxiety states and 20 normal controls matched for age and sex. After a rest period, 20 identical auditory stimuli were applied automatically at intervals varying from 45 to 80 seconds to form a standard habituation procedure.

The background skin conductance levels tended to rise throughout the recording session in the patients whereas it fell in the normal group. Habituation of the psycho-galvanic reflexes to the stimuli was much less rapid in the patients. Spontaneous skin conductance fluctuations were more frequent in the patients.

Three variables-change in conductance during the experiment, rate of habituation, and the number of fluctuations at the end of the experiment-were combined in a discriminant-function analysis. The scores obtained correlated significantly with independent ratings of overt anxiety made immediately before the physiological recordings.

A preliminary theory of the mechanism of anxiety based on the relationship between central nervous system activity and the rate of habituation was outlined.
This work was supported by grant No. MY-3561 froro the National Institute of Mental Health of the U.S. Public Health Service.

The authors wish to acknowledge their indebtednesf to Professor H. O. Schild and Dr. M. Shepherd for theof advice and encouragement.

\section{REFERENCES}

Ackner, B. (1956). J. psychosom. Res., 1, 21.

Darrow, C. W. (1933). Amer. J. Psychiat., 90, 285.

-, and Solomon, A. P. (1934). Arch. Neurol. Psychiat. (Chic.), 32 273.

Davis, J. F., Malmo, R. B., and Shagass, C. (1954). Canad. J. Psycho $8,177$.

Ellingson, R. J. (1954). Amer. J. Psychiat., 111, 263.

Fisher, R. A. (1954). Statistical Methods for Research Worker 12 th ed., p. 285. Hafner, New York.

Head, H. (1923). Brit. J. Psychol., 14, 126.

Hoch, P., Kubis, J. F., and Rouke, F. L. (1944). Psychosom. Med., 237.

Howe, E. S. (1958). J. abnorm. soc. Psychol., 56, 183.

Jurko, M., Jost, H., and Hill, T. S. (1952). J. Psychol., 33, 183.

Lader, M. H. (1964). Brain, in the press.

, M. H. (1964). Brain, in the press. and Montagu, J. D. (1962). J. Neurol. Neurosurg. Psychiat., $2 \overrightarrow{⿱ 乛}$ 126.

Lewis, A. (1956). In Price's Textbook of the Practice of Medicine, 9 ed., edited by Donald Hunter, p. 1678. Oxford University Prese London.

Lykken, D. T. (1959). J. comp. physiol. Psychol., 52, 629.

Malmo, R. B. (1957). Psychol. Rev., 64, 276.

- (1959). Ibid., 66, 367.

-, and Shagass, C. (1949). Psychosom. Med., 11, 9. —, Davis, J. F., Cleghorn, R. A., Graham, B. F., Thinges Goodman, A. J. (1948). Science, 108, 509.

,-- , and Heslam, R. M. (1951). Canad. J. Psychol., 5, 16 范

Odegaard, O. (1932). Brit. J. med. Psychol., 12, 132.

Scholander, T. (1960). Acta physiol. scand., 50, 259.

Siegel, S. (1956). Nonparametric Statistics for the Behavioral Scieness McGraw-Hill, New York.

Snedecor, G. W. (1956). Statistical Methods, 5th ed. State Coget Press, Ames, Iowa.

Solomon, A. P., and Fentress, T. L. (1934). J. nerv. ment. Dis., 80, 63.

Stewart, M. A., Winokur, G., Stern, J. A., Guze, S. B., Pfeiffer, E $\widetilde{\sigma}^{\text {grnd }}$ Hornung, F. (1959). J. ment. Sci., 105, 1102.

Wilder, J. (1958). Amer. J. Psychother., 12, 199. (1962). Ann. N.Y. Acad. Sci., 98, 1211.

Wishner, J. (1953). J. abnorm. soc. Psychol., 48, 253. 